\title{
AWARENESS AND PRACTICE OF PHYSICAL ACTIVITY AMONG MALE MEDICAL UNDERGRADUATES AT MAJMAAH UNIVERSITY, SAUDI ARABIA
}

\author{
Muhammad Asad Farhan, Syed Yousaf Kazmi, Abdul Irfan, Waqas Sami, Ali Faraz, Muhammad Imran Ali
}

Majmaah University, Al Majmaah, Saudi Arabia

\section{ABSTRACT}

\begin{abstract}
Objective: To probe the level of awareness and practice of the WHO recommendation for physical activity among male medical undergraduates at Majmaah University, Saudi Arabia.

Study Design: Cross-sectional analytical study.

Place and Duration of Study: College of Medicine, Majmaah University, Kingdom of Saudia Arabia from Oct to Dec 2018. Methodology: The study was conducted amongst 150 undergraduate medical students using a self-validated questionnaire. Results: A total of $53(35.33 \%)$ participants were found to be physically inactive while only $18(12 \%)$ participants were adherent to WHO recommendations of physical activity for health benefits. Only 31 (20.66\%) participants were correctly aware of the WHO guidelines for physical activity with health benefits. Football $(n=47)$ and table tennis $(n=20)$ were the sports played by the majority i.e., in $67(44.66 \%)$ participants. The physically active participants encouraged peers for physical activity and preferred social media as a mean of spreading awareness about physical activity.

Conclusion: The awareness and the level of adherence of our male medical undergraduate students of physical activity according to the WHO's guidelines are at par with the results of the national studies but much lower than the developed countries like the USA.
\end{abstract}

Keywords: Medical students, Physical activity, WHO guidelines for physical study.

How to Cite This Article: Farhan MA, Kazmi SY, Irfan A, Sami W, Faraz A, Ali MI. Awareness And Practice of Physical Activity Among Male Medical Undergraduates At Majmaah University, Saudi Arabia. Pak Armed Forces Med J 2021; 71(5): 1669-1675. doi: https://doi.org/10.51253/pafmj.v71i5.3864

This is an Open Access article distributed under the terms of the Creative Commons Attribution License (https://creativecommons.org/licenses/by-nc/4.0/), which permits unrestricted use, distribution, and reproduction in any medium, provided the original work is properly cited.

\section{INTRODUCTION}

By the turn of the new millennium, World health Organization (WHO) noticed an upsurge of non-communicable diseases (NCDs), including hypertension, diabetes mellitus, coronary artery diseases, obesity, metabolic syndrome, along with breast and colon cancer. ${ }^{1}$ The rise of these NCDs is linked to increased preference of the worldwide populace for a sedentary lifestyle. These NCDs are preventable by a change in lifestyle with the use of physical activity (PA). ${ }^{2}$

PA is defined as "any bodily movement produced by skeletal muscles that result in energy expenditure." The term exercise, on the other hand, is a subdivision of PA that may be expressed as a planned, structured, and repetitive PA for the purpose of improvement or maintenance of one or more components of physical fitness. $^{3}$

PA is associated not only with a subjective feeling of wellbeing but also with the objective risk reduction of NCDs. For the prevention of NCDs, WHO proposes PA guidelines addressing the general population for three age groups: 5-17 years, $18-64$ years, and 65 years

Correspondence: Dr Muhammad Asad Farhan, PO Box 66, College of Medicine, Majmaah University, Al-Majmaah, Saudi Arabia

Received: 12 Feb 2020; revision received: 04 May 2020; accepted: 14 May 2020
\& older. For the age group 18-64 years, WHO recommends that "individuals should engage for a minimum of 150 minutes of moderate-intensity aerobic PA per week or 75 minutes of vigorous-intensity aerobic PA in a week or an equal combination of two in a bout of at least 10 minutes. Also, muscle-strengthening activities should be undertaken for two or more days per week". ${ }^{4}$

Since the introduction of WHO guidelines for PA, numerous studies were carried out to determine the level of PA in various subsets of the population in different countries. For example, a study conducted in 2014 on 475 healthy adults in Germany found that only $14 \%$ adhered to the WHO guidelines. ${ }^{5}$ Similarly, in a sample size of 51 adult students of the University of Manitoba, Canada, $69 \%$ of individuals perceived themselves as moderate to vigorous-intensity PA achievers, yet only $34.6 \%$ of participants were following the WHOs guidelines when muscle-strengthening activities were also considered. ${ }^{6}$ Around $64.5 \%$ of USA adults are physically active that met the WHO PA criteria, whereas, in various European countries, the PA levels among the population were much lower. ${ }^{7,8}$

Kingdom of Saudi Arabia (KSA) had seen colossal economic development in the recent past. This transformation had attracted Saudi nationals to adopt 
westernized ways of living with a resultant decline in the overall level of PA. In fact, recent national studies reflect this decreasing PA trend evident by an upsurge of NCDs in the past few decades. In one study on a sample size of 10,735 Saudis adults across the whole KSA, only $12.9 \%$ of the participants met the WHO standard of moderate-intensity PA with health benefits. ${ }^{9}$ This general decline PA tendency is also repercussed in the university students in KSA, whereas in 2014, a study conducted on 1257 students in a medical university of KSA showed that only $14.8 \%$ of the participants were highly active physically. ${ }^{10}$ We examined the regional and local studies carried out earlier and found that investigators relied on information of physical activity based upon the response about leisure time activities, gym workouts, occupation-related physical activity, whereas very few researchers strictly considered WHO's guidelines of PA in their studies. Therefore, the present study was conducted with the objective to determine the level of awareness and practice of the WHO's recommendation for physical activity among male medical undergraduates of the College of Medicine, Majmaah University, KSA.

\section{METHODOLOGY}

A cross-sectional analytic study of a three-month duration was conducted at the College of Medicine, Majmaah University, KSA, from October to December 2018. The level of precision formula was used to calculate the sample size $n=z^{2}(p q) / e^{2}$ where $n=$ required sample size, $p=$ prevalence, $\mathrm{e}=$ margin of error, $\mathrm{z}=$ standard normal distribution, confidence interval $=95 \% .{ }^{11}$ After placing the following values (where, $p=0.12$, e= $0.05, q=0.88(1-p), z=1.96)$, the sample size of 163 was yielded. ${ }^{10}$ Non probability consecutive sampling technique was used.

Inclusion Criteria: Male medical undergraduate students from all five years were included in the study. The complete enumeration sampling method was used for data gathering. The participation was purely voluntary, and only those medical students were included who consented for the study.

Exclusion Criteria: Participants was who were suffering from any medical or surgical condition that might preclude them from taking part in PA.

Ethical approval of the study was obtained from the Majmaah Research Institutional Ethics Committee of Basic \& Health Science, Research Center Majmaah (approval no: MUREC-Nov 29/COM-2017/ 24). A selfvalidated questionnaire was used to collect the data from the study subjects. The first part of the questionnaire included demographic information, while the second part comprised questions related to physical activity. A trained research fellow was assigned the task to collect the data from the students. After taking verbal consent, the purpose of the study was explained to the students, and different parameters were clarified. The participants were asked to fill the form based on a recall of their PA of the past one-week. The identity of the participants was kept confidential. There were ten questions addressing the PA, which were all closedend, e.g., "On an average, how much physical activity do you perform each week (in minutes)?" The response to this question was noted, and the study participants were categorized as Inactive (performing PA $<70 \mathrm{~min} /$ week), insufficiently active (PA duration 70-150 min/week), active (PA duration 150$300 \mathrm{~min} /$ week), and highly active (PA duration $>300$ $\mathrm{min} /$ week). ${ }^{12}$

The English version of the questionnaire was translated into Arabic language by professional translators. The Arabic version of the questionnaire was retranslated to the English language by a third party, and then both questionnaires were matched to rule out any significant disagreement.

The data were entered and analyzed using SPSS25 . Frequencies and percentages are reported for qualitative variables, whereas quantitative variables have been expressed as mean with standard deviation. Pearson chi-square and Fisher Exact test were applied to observe associations between qualitative variables. Ordinal Logistic Regression with a Backward Conditional Approach was applied to see the effect of physical activity on other study parameters. The $p$-value of $\leq 0.05$ was considered statistically significant.

\section{RESULTS}

The number of male medical undergraduate students at the time of the study was 172, and all of them were included. A total of 156 students $(90.69 \%)$ returned the form, out of which six were incomplete and were excluded from the study. Therefore, the final sample size of our study was 150 .

The mean age of the participants was $22.56 \pm$ 4.31 years. The self-declared physical inactivity (PinA) among our participants was $29.3 \%(n=44)$, whereas 29 study participants $(19.33 \%)$ considered themselves to be active or highly active. The level of PA was highest in the first year, and it decreased considerably in the subsequent years of studies. When the duration of PA per week was considered, thirty-seven out of 150 students $(24.66 \%)$ were performing moderate to vigorous 
degree PA of more than 150 minutes per week (TableI). The students who met the WHO's criteria of performing more than 150 minutes of moderate degree PA plus muscle-strengthening exercise twice a week were only $18(12 \%)$.

Table-I: Weekly time spent in physical activity and use of muscle stretching exercise.

\begin{tabular}{l|c|c}
\hline \multicolumn{2}{l|}{$\begin{array}{l}\text { Overall weekly time spent in physical } \\
\text { activity }\end{array}$} & $\begin{array}{c}\text { Muscle Stretching } \\
\text { Exercise }\end{array}$ \\
\hline Minutes per week & Frequency $\mathrm{n}(\%)$ & $\mathrm{n}(\%)$ \\
\hline$<70$ (Inactive) & $53(35.33)$ & $9(6)$ \\
\hline $\begin{array}{l}70-150 \text { (Insufficiently } \\
\text { Active) }\end{array}$ & $60(40)$ & $16(10.66)$ \\
\hline $\begin{array}{l}>150 \text { (Active \& } \\
\text { Highly Active) }\end{array}$ & $37(24.66)$ & $18(12)$ \\
\hline Total & $150(100)$ & $43(28.66)$ \\
\hline
\end{tabular}

participants $18(48.6 \%)$ who were active and highly active were going to the gym, whereas, majority of the participants who were insufficiently active $44(73.3 \%)$ and inactive $43(81.1 \%)$ were not going to gym ( $p=$ 0.008).

Results presented in Table-III, showed that a significant association was observed between physical activity and performing the aerobic exercise $(p<0.001)$ showing that majority of the participants $25(67.6 \%)$ who were active and highly active were performing aerobic exercise, followed by active group 23 (38.3\%). Moreover, a significant association was observed between performing physical activity and encouraging peers $(p=0.007)$, showing that most of the participants who were highly active also encouraged their peers

Table-II: Relationship between physical activeness and various factors $(n=150)$.

\begin{tabular}{|c|c|c|c|c|c|}
\hline \multicolumn{6}{|c|}{ Physical Activeness } \\
\hline & Inactive $\mathbf{n}(\%)$ & Insufficiently Active n (\%) & Active \& Highly Active n (\%) & Total & $p$-value \\
\hline \multicolumn{6}{|l|}{ Age } \\
\hline$<30$ years & $53(100)$ & $59(98.3)$ & $36(97.3)$ & 148 & \multirow{2}{*}{$\begin{array}{c}X^{2}=1.29 \\
p=0.524\end{array}$} \\
\hline $30-40$ years & - & $1(1.7)$ & $1(2.7)$ & 2 & \\
\hline \multicolumn{6}{|l|}{ Sports } \\
\hline Football & $11(20.8)$ & $20(33.3)$ & $16(43.2)$ & 47 & \multirow{8}{*}{$\begin{array}{c}X^{2}=51.56 \\
p<0.001\end{array}$} \\
\hline Table Tennis & $6(11.3)$ & $11(18.3)$ & $3(8.1)$ & 20 & \\
\hline Brisk Walk & $2(3.8)$ & $9(15.0)$ & $7(18.9)$ & 18 & \\
\hline Swimming & $4(7.5)$ & $4(6.7)$ & $3(8.1)$ & 11 & \\
\hline Housework & $2(3.8)$ & $6(10.0)$ & $2(5.4)$ & 10 & \\
\hline Jogging / Running & $2(3.8)$ & $7(11.7)$ & $5(13.5)$ & 14 & \\
\hline Cricket & $1(1.9)$ & $1(1.7)$ & - & 2 & \\
\hline None & $25(47.2)$ & $2(3.3)$ & $1(2.7)$ & 28 & \\
\hline \multicolumn{6}{|l|}{ Gym } \\
\hline Yes & $10(18.9)$ & $16(26.7)$ & $18(48.6)$ & 44 & \multirow{2}{*}{$\begin{array}{l}X^{2}=9.66 \\
p=0.008\end{array}$} \\
\hline No & $43(81.1)$ & $44(73.3)$ & $19(51.4)$ & 106 & \\
\hline \multicolumn{6}{|c|}{ Awareness all-Cause Mortality \& PiA } \\
\hline$<10 \%$ & $16(30.2)$ & $5(8.3)$ & $2(5.4)$ & 23 & \multirow{5}{*}{$\begin{array}{c}X^{2}=20.68 \\
p=0.005\end{array}$} \\
\hline $10-20 \%$ & $4(7.5)$ & $11(18.3)$ & $2(5.4)$ & 17 & \\
\hline $20-30 \%$ & $17(32.1)$ & $16(26.7)$ & $12(32.4)$ & 45 & \\
\hline $30-40 \%$ & $10(18.9)$ & $16(26.7)$ & $13(35.1)$ & 39 & \\
\hline $40-50 \%$ & $6(11.3)$ & $12(20.0)$ & $8(21.6)$ & 26 & \\
\hline \multicolumn{6}{|c|}{ Awareness WHO Guideline of PA } \\
\hline Yes & $21(39.6)$ & $23(38.3)$ & $19(51.4)$ & 63 & \multirow{2}{*}{$\begin{array}{l}X^{2}=1.78 \\
p=0.410\end{array}$} \\
\hline No & $32(60.4)$ & $37(61.7)$ & $18(48.6)$ & 87 & \\
\hline
\end{tabular}

Results presented in Table-II, showed a significant association between physical activity and playing sports $(p<0.001)$. We can see that the majority of the participants who were active and highly active were playing football, doing the brisk walk, swimming, and jogging/running. Playing football was still the preferred sport in the group of students who were insufficiently active or inactive. However, table tennis was the second most liked sports in this group. Most of the
$35(94.6 \%)$, followed by those who were active 49 (81.7\%). However, no significant association was observed between the level of physical activity and awareness about the WHO criteria for achieving health benefits from PA $(p=0.410)$ and source of information for disseminating the health benefits to the general masses $(p=0.784)$.

About the type of PA performed by the participants, playing football was the most popular PA 
$(n=47)$, followed by playing table tennis $(n=20)$, brisk walking $(n=18)$, jogging $(n=14)$, swimming $(n=11)$, and playing cricket $(n=2)$. For the question "Are you aware of any guidelines for physical activities (e.g., WHO Guidelines)," 85 participants $(57.43 \%)$ had not heard about the WHO criteria for PA, while only 31 out of the remaining 63 participants who knew about these guidelines could correctly define them.
Ninety-two participants were aware of the aerobic physical activity while fifty-three were doing it. In reply to the question "In your opinion, how much PinA increases the risk of all-cause mortality compared to those who engage according to the WHO criteria of PA?", forty-five participants (30\%) knew the correct all-cause mortality risk due to PinA, while 105 participants $(70 \%)$ were oblivious to the correct risk

Table-III: Relationship between physical activeness and various factors $(n=150)$.

\begin{tabular}{|c|c|c|c|c|c|}
\hline \multicolumn{6}{|c|}{ Physical Activeness } \\
\hline & Inactive $\mathrm{n}(\%)$ & Insufficiently Active n (\%) & Active \& Highly Active n (\%) & Total & $p$-value \\
\hline \multicolumn{6}{|l|}{ Source of Information } \\
\hline TV & $5(9.4)$ & $8(13.3)$ & $6(16.2)$ & 19 & \multirow{5}{*}{$\begin{array}{l}X^{2}=4.73 \\
p=0.784\end{array}$} \\
\hline Social Media & $36(67.9)$ & $39(65.0)$ & $26(70.3)$ & 101 & \\
\hline Print Media & $2(3.8)$ & $1(1.7)$ & $0(0.0)$ & 3 & \\
\hline Community Campaigns & $9(17.0)$ & $9(15)$ & $3(8.1)$ & 21 & \\
\hline Signposting & $1(1.9)$ & $3(5)$ & $2(5.4)$ & 6 & \\
\hline \multicolumn{6}{|l|}{ Aerobic Exercise } \\
\hline Yes & $6(11.3)$ & $23(38.3)$ & $25(67.6)$ & 54 & \multirow{2}{*}{$\begin{array}{c}\mathrm{X}^{2}=30.15 \\
p<0.001\end{array}$} \\
\hline No & $47(88.7)$ & $37(61.7)$ & $12(32.4)$ & 96 & \\
\hline \multicolumn{6}{|l|}{ Encourage Peers } \\
\hline Yes & $36(67.9)$ & $49(81.7)$ & $35(94.6)$ & 120 & \multirow{2}{*}{$\begin{array}{l}X^{2}=9.80 \\
p=0.007\end{array}$} \\
\hline No & $17(32.1)$ & $11(18.3)$ & $2(5.4)$ & 30 & \\
\hline
\end{tabular}

Table-IV: Association between physical activity and factors using ordinal logistic regression with backward conditional approach.

\begin{tabular}{|c|c|c|c|c|c|c|}
\hline & \multirow{2}{*}{$\beta$} & \multirow{2}{*}{ Wald } & \multirow{2}{*}{$p$-value } & \multirow{2}{*}{ Odds Ratio } & \multicolumn{2}{|c|}{ 95\% CI for Odds } \\
\hline & & & & & Lower & Upper \\
\hline \multicolumn{7}{|l|}{ Age } \\
\hline$<30$ years & -4.1 & 1.66 & 0.198 & 1.995 & 0.691 & 2.353 \\
\hline \multicolumn{7}{|l|}{ Sports } \\
\hline Foot Ball & 2.63 & 7.72 & $0.005^{*}$ & 1.777 & 1.974 & 4.498 \\
\hline Brisk Walk & 4.29 & 17.1 & $<0.001^{*}$ & 2.118 & 2.261 & 6.33 \\
\hline Housework & 2.65 & 5.77 & $0.016^{*}$ & 0.443 & 0.125 & 0.886 \\
\hline Jogging / Running & 2.92 & 7.41 & $0.006^{*}$ & 1.851 & 1.581 & 3.662 \\
\hline Foot Ball & 1.94 & 3.73 & 0.053 & 1.992 & 0.471 & 2.118 \\
\hline Brisk Walk & 2.06 & 3.39 & 0.065 & 0.765 & 0.112 & 1.901 \\
\hline Housework & -0.5 & 0.05 & 0.819 & 0.356 & 0.021 & 0.993 \\
\hline \multicolumn{7}{|l|}{ Avail Gym } \\
\hline Yes & 0.1 & 0.03 & 0.554 & 1.711 & 0.186 & 3.881 \\
\hline \multicolumn{7}{|l|}{ Awareness Death Risk } \\
\hline$<10 \%$ & -0.2 & 0.03 & 0.884 & 1.777 & 0.662 & 2.927 \\
\hline $10-20 \%$ & 0.48 & 0.27 & 0.598 & 2.118 & 1.369 & 3.335 \\
\hline $20-30 \%$ & 5.76 & 23.6 & $0.004^{*}$ & 2.669 & 1.981 & 4.881 \\
\hline $30-40 \%$ & 0.63 & 0.69 & 0.405 & 1.851 & 1.215 & 2.061 \\
\hline \multicolumn{7}{|l|}{ Awareness WHO Criteria } \\
\hline Yes & 0.08 & 0.03 & 0.853 & 0.337 & 0.119 & 2.917 \\
\hline \multicolumn{7}{|l|}{ Source of Information } \\
\hline TV & -1.1 & 0.69 & 0.404 & 0.119 & 0.041 & 2.182 \\
\hline Social Media & -1.1 & 0.73 & 0.393 & 1.81 & 0.991 & 2.441 \\
\hline Print Media & -1.1 & 0.24 & 0.623 & 2.44 & 0.13 & 3.089 \\
\hline Community Campaigns & -2 & 2.17 & 0.14 & 1.942 & 0.271 & 2.001 \\
\hline \multicolumn{7}{|l|}{ Aerobic Exercise } \\
\hline Yes & 1.09 & 3.82 & $0.005^{*}$ & 2.611 & 1.933 & 4.061 \\
\hline \multicolumn{7}{|l|}{ Encourage Peers } \\
\hline Yes & 0.51 & 0.71 & $0.021^{*}$ & 3.774 & 2.172 & 5.995 \\
\hline
\end{tabular}


associated with PinA. In response to the question "How would you like to spread the information about physical activity?" most of the students $(n=122)$ believed that social media and community-wide campaigns could be the most effective way of disseminating awareness about physical activity. To another question "Do you encourage community and peers for physical activity?", 120 (80\%) participants replied in affirmative.

Playing foot ball (OR=1.113 [95\% CI: 1.974-4.498), Wald $\left.\chi^{2}(7)=7.72, p=0.005\right)$, doing brisk walk $(\mathrm{OR}=2.118$ [95\% CI: 2.261-6.330), Wald $\left.\chi^{2}(7)=17.1, p<0.001\right)$, housework (OR=0.443 [95\% CI: 0.125-0.886), Wald $\chi 2(7)=$ 5.77, $p=0.016)$ and performing jogging/running $(\mathrm{OR}=$ 1.851 [95\% CI: 1.581-3.662), Wald $\chi^{2}(7)=7.41, p=0.006$ ) were significant predictors of being highly active. Performing aerobic exercise (OR=2.611 [95\% CI:1.9334.061), Wald $\left.\chi^{2}(1)=3.82, p=0.005\right)$ and encouraging peers $\left(\mathrm{OR}=3.774\right.$ [95\% CI: 2.172-5.995), Wald $\chi^{2}(1)=$ $0.71, p=0.021)$ were significant predictors of being highly active. The results were presented in Table-IV.

\section{DISCUSSION}

Aerobic PA involves the body's large muscles moving in a rhythmic fashion for an uninterrupted time period. Examples include a brisk walk, jogging, bicycling, swimming, etc. Muscle-strengthening PA involves working or holding of the body's muscles against some resistance. Examples include resistance exercises and weightlifting. ${ }^{13}$

The moderate-intensity PA is the one in which there is a small increase in breathing and heart rate, e.g., brisk walking, whereas vigorous-intensity PA involves hard physical exertion with a significant increase in breathing and heart rate for example playing football, running etc. ${ }^{14,15}$

The results showed that $44(29.72 \%)$ medical undergraduates perceived themselves to be physically inactive, while 53 participants $(35.33 \%)$ were performing PA less than 70 minutes per week. This is in contrast to a similar study carried out in 2014-15 on 450 healthcare students of Majmaah University with physical inactivity approaching $62.4 \% .^{16}$ Another study carried out on female students in King Khalid University Abha in 2012-13 using the General Practice Physical Activity Questionnaire (GPPAQ), where $58 \%$ of students were found to be physically inactive. ${ }^{17}$ The reasons for a low level of PinA in our study could be explained because, in the above-mentioned studies, physical inactivity was calculated based on the use of either GPPAQ or a self-validated questionnaire that do not correspond strictly to the WHO's criteria of PinA.
And also, that the PinA in female students related to the medical profession approaches $60 \%$ as found in various national studies; ${ }^{18}$ therefore, this factor could also cater to the present results as female students were not included in the study.

The level of adherence of our study participants to the WHO's guidelines of PA with significant health benefits was only $12 \%$. A study conducted in Riyadh in adolescents in high school KSA revealed that 70 students $(15.5 \%)$ were involved in a moderate degree PA five times or more per week. ${ }^{19}$ Similarly, another study conducted on the general population of 18-65 years in the Al-Hassa region, KSA on a sample size of 2176 Saudi adults, the level of PA with health benefits was $10.4 \% .{ }^{20}$ Among university health college students at King Khalid University, KSA a study revealed adherence to WHO recommendations PA level of $14.8 \%$ \& $13.4 \%$ for moderate and vigorous-intensity PA respectively..$^{10}$ Another study at Majmaah University, KSA, conducted on a sample size of 450 medical students; about $37.6 \%$ of students were engaged in regular PA, while only $7.3 \%$ of students exercised five times per week. This study does not cater for the two days of resistance exercise per week criteria of WHO recommendation; hence, the actual percentage might be lower. We considered the minimum two days muscle strengthening WHO criteria for PA that other studies did not contemplate. Although $24.66 \%$ of participants in our study adhered to the PA duration criteria of performing >150 minutes of moderate to vigorous-intensity PA per week, yet only $12 \%$ were also performing recommended muscle strengthening exercise.

The type of sports participation in our participants showed that majority of them preferred to play football even by the group stratified as insufficiently active and inactive $47(31 \%)$, followed by table tennis $20(13.33 \%)$, brisk walking $18(12 \%)$, and swimming 11 $(7.3 \%)$. This finding is in conformity to the other local studies where football is the most preferred sport by the youth of KSA. ${ }^{21}$ Football is the sport loved by the whole Arab world, and the KSA government promotes this sport among the youth by the construction of numerous football grounds in each municipality. Visiting gym was a trend seen most frequently by the active and highly active group, while the converse inclination was noted among the insufficiently active and inactive fraction.

The study results about adherence to recommended PA levels were consistent with the local studies but were disappointingly lower when compared to 
developed countries like the USA, where around 84\% of medical students engaged in PA levels. ${ }^{22}$ The main factors responsible for low adherence of PA standards in KSA compared to the developed world were lack of awareness of health benefits of PA and various factors related to a sedentary lifestyle, e.g., subsidized oil prices, lack of abundance of public transport with a resultant higher number of cars per family, cheap eatery in the market, availability of fast food at doorsteps, etc. ${ }^{20}$

Regarding the awareness about the WHOs recommendation of PA, 63 students (42\%) heard about the WHO's guidelines of PA for health benefits while only $31(20.33 \%)$ could correctly describe it. The corresponding level of awareness in University healthcare college students at Cairo University, Egypt, was 11.9\%, ${ }^{23}$ while it was lower in other countries like the UK $18 \%$ \& India $9.3 \% .{ }^{24}$ These results about awareness of WHO's PA guidelines were a little higher at $20.33 \%$ because the study participants were medical students who were taught the topic in the fourth year MBBS program in the block of Youth, elderly, and society module.

The all-cause mortality associated with PinA approaches $20-30 \%$ when compared with those individuals who were physically active as per the WHO's guidelines of $\mathrm{PA}^{25}$. We asked this question from the participants, and the results showed that 45 participants $(30 \%)$ correctly identified the increase in the risk. This awareness was due to the fact that the topic of PA was being given exclusive coverage in the curriculum of the college of medicine Majmaah University, KSA.

The comparative statistics showed that the participants who were physically active and highly active were performing aerobic exercise and were also more likely to encourage peers for PA. Majmaah is a small city with an educational hub, and the city municipality is devoted to providing the best services of PA to the general public. There are a number of gyms and sports arenas everywhere in the city, and university campuses have sports facilities like table tennis rooms where students spend their free time in sports activities. The overall environment is dynamic for PA and this is the reason for the medical undergraduates who encourage peers for PA. The participants believed that social media and community campaigns were the best media for the spread of awareness of PA benefits to the public. The medical undergraduates are regularly involved in community campaigns as part of their preclinical and clinical modules, namely public health \& epidemiology course, family medicine, internal medicine, etc. This was encouraging that the students of the college of medicine Majmaah University wished to disseminate the awareness to the public through modern electronic sources as well as through community campaigns.

Considering the lack of awareness about the health benefits of PA and the high level of PinA in the public of KSA, it is essential that the topic of PA and its benefits should be addressed in the country like KSA where the NCDs are on the rise. More effort is required by the education sector to incorporate the topic of PA in the curriculum of primary and secondary schools in KSA. Moreover, the playing facilities in the educational campuses should be increased, and special marks should be allocated for extra-curricular sports activities. In the Majmaah University campus, the facilities of the gym are lacking, and efforts should be undertaken for providing the facilities so that the students engage themselves in a moderate degree of PA in the free time in the college. More indoor sports arenas should be allocated for activities like table tennis, badminton, handball, volleyball, etc.

\section{LIMITATION OF STUDY}

Our study sample size was small, and this could result in a type 2 error. The study did not include female participants because there were administrative and social difficulties in liaising with the female students in their campus. The study was a cross-sectional one, and the participants' data was based on selfreporting, which could result in recall bias. Moreover, the study questionnaire was tailored according to the researchers' requirements, and authors did not follow the previously used questionnaires, e.g., IPAQ or GPAQ, etc. because those questionnaires covered a lot of information not related to the objectives of the study. For this reason, the study results about PA might not exactly equate with similar studies carried out earlier. Also, the present study was limited to the college of medicine; therefore, the results could not be generalized and extrapolated at the national level.

\section{RECOMMENDATIONS}

To disseminate the information about the health benefits of PA in the general public of KSA, a herculean effort from health and education sectors is required through integration of the topic of PA and its health benefits in the curriculum of the schools and universities, utilization of the social media, and initiation of community campaigns by the universities. 


\section{CONCLUSION}

Although the awareness and the level of adherence of our male medical undergraduate students to PA according to the WHO's guidelines was at par with the results of the national studies yet it was much lower than the developed countries like the USA. The preference to engage in sports activities and gym workouts by the study participant group is encouraging.

\section{Conflict of Interest: None.}

\section{Authors' Contribution}

MAF: Concpeption, design, SYK: Data design, AI: Data design, WS: Interpretation of data, AF: Data acuisition, MIA: Data approval

\section{REFERENCES}

1. Pratt M, Norris J, Lobelo F. The cost of physical inactivity: moving into the 21st century. Br J Sports Med 2014; 48(3): 171-173.

2. Aspinall S, Munro A. Knowledge and global health: reducing the burden of non-communicable diseases using physical activity. $\mathrm{Br}$ J Sports Med 2019; 53(2): 845-846.

3. Mandil AM, Alfurayh NA, Aljebreen MA. Physical activity and major non-communicable diseases among physicians in Central Saudi Arabia. Saudi Med J 2016; 37(11): 1243-1250.

4. WHO. Global health recommendations on physical activity for health. Geneva. 2010, [Internet] Available from: http:// whqlibdoc.who.int/publications/2010/9789241599979_eng.pdf [Cited 2020 May 01].

5. Luzak A, Heier M, Thorand B, Laxy M, Nowak D. Physical activity levels, duration pattern and adherence to WHO recommendations in German adults. PLoS One 2017; 12(2): e0172503.

6. Prokop NW, Hrubeniuk TJ, Senechal M, Bouchard DR. People who perceive themselves as active cannot identify the intensity recommended by the international physical activity guidelines. Open Access J Sports Med 2014; 5(1): 235-241.

7. Stanford FC, Durkin MW, Stallworth JR, Blair SN. Comparison of physical activity levels in physicians and medical students with the general adult population of the United States. Phys Sportsmed 2013; 41(4): 86-92.

8. Hansen BH, Kolle E, Dyrstad SM, Holme I, Anderssen SA. Accelerometer-determined physical activity in adults and older people. Med Sci Sports Exerc 2012; 44(2): 266-272.

9. El Bcheraoui C, Tuffaha M, Daoud F, Kravitz H, Al Mazroa MA, $\mathrm{Al}$ Saeedi M, et al. On Your Mark, Get Set, Go: Levels of Physical Activity in the Kingdom of Saudi Arabia, 2013. J Phys Act Health 2016; 13(2): 231-238.

10. Awadalla NJ, Aboelyazed AE, Hassanein MA, Khalil SN, Aftab R. Assessment of physical inactivity and perceived barriers to physical activity among health college students, south-western Saudi Arabia. East Mediterr Health J 2014; 20(10): 596-604.

11. Sami W, Al-Rukban MO, Almansour M, Waqas T, Afzal K, Asad R. How many subjects should be studied: sample size determi- nation through hypothesis testing and confidence interval. Majmaah J Health Sci 2013; 1(2): 43-48.

12. ODPHP. Physical Activity Guidelines for Americans. Office of Disease Prevention and Health Promotion.2018 2nd edition, [Internet] Available from: https://health.gov/paguidelines/ second-edition/[Cited 2020 May 01].

13. Elsayed YMH. Physical Inactivity and Clinical Cardiovascular Impact-Updating Narrative Review. Worldw Med 2019; 1(4): 123-143.

14. Ahmed HS, Khalid ME, Osman OM, Ballal MA, Al-Hashem FH. The association between physical activity and overweight and obesity in a population of children at high and low altitudes in Southwestern Saudi Arabia. J Family Commun Med 2016; 23(2): 82-87.

15. Abo Zaid HA, Farahat FM. Physical activity profile among patients attending family medicine clinics in western Saudi Arabia. Saudi Med J 2010; 31(4): 428-433.

16. Alfhaid F, Alzahrani M, Almansour M, Alghamdi T, Ansari T, Sami W, et al. Lifestyle of health sciences students at Majmaah University, Saudi Arabia. Australian Med J 2017; 10(2): 111.

17. Saleem SAA, Alahmari RS, Alahmari MS. Dietary habits among female medical student in King Khalid University, Abha City, 2014, Int J Med Sci Public Health 2016; 5(1): 1268-1274.

18. Al-Hazzaa HM, Al-Sobayel HI, Abahussain NA, Qahwaji DM, Alahmadi MA, Musaiger AO. Association of dietary habits with levels of physical activity and screen time among adolescents living in Saudi Arabia. J Hum Nutr Diet 2014; 27(s2): 204-213.

19. Alsubaie AS, Omer EO. Physical activity behavior predictors, reasons and barriers among male adolescents in riyadh, saudi arabia: evidence for obesogenic environment. Int J Health Sci (Qassim) 2015; 9(4): 400-408.

20. Amin TT, Al Khoudair AS, Al Harbi MA, Al Ali AR. Leisure time physical activity in Saudi Arabia: prevalence, pattern and determining factors. Asian Pac J Cancer Prev 2012; 13(1): 351-360.

21. Peleias M, Tempski P, Paro HB, Perotta B, Mayer FB, Enns SC, et al. Leisure time physical activity and quality of life in medical students: results from a multicentre study. BMJ Open Sport Exerc Med 2017; 3(1): e000213.

22. Stanford FC, Durkin MW, Blair SN, Powell CK, Poston MB, Stallworth JR. Determining levels of physical activity in attending physicians, resident and fellow physicians and medical students in the USA. Br J Sports Med 2012; 46(5): 360-364.

23. Amin TT, Mohamed Abdelmoaty A, Fouad Abd El Badei A, Obaid HA, Mohamed EM, abosheab A, et al. Role of leisure time physical activity in cancer prevention: awareness and practice among medical students at cairo university. Asian Pac J Cancer Prev 2017; 18(1): 135-143.

24. Abdeta C, Seyoum B, Teklemariam Z. Knowledge of the physical activity guidelines and factors associated with physical activity participation among adults in Harar town, eastern Ethiopia. BMJ Open Sport \& amp; Exerc Med 2019; 5(1): e000463.

25. Lan C, Wolf SL, Tsang WWN. Tai chi exercise in medicine and health promotion. J Evid Based Complementary Altern Med 2013; 2013(5): 298768. 